\title{
MULTIMEDIA AND CONVERGENCE AS FACTORS OF THE DEVELOPMENT OF REGIONAL INTERNET MEDIA (ON THE EXAMPLE OF THE MASS MEDIA OF THE REPUBLIC OF TATARSTAN)
}

\author{
Tatiana A. Nagovitsyna ${ }^{1}$ \\ Ramis R. Gazizov²
}

\begin{abstract}
The authors focus on such properties of regional Internet media as multimedia and convergence, which fully meet the requirements of the modern media market. Covering this topic, the authors focus on Internet publications of the Republic of Tatarstan. The specifics of the Internet media significantly changed the work of the journalists themselves, the nature of the submission of materials, the target audience, and the whole system of functioning of the media in general. The authors state that in recent years there has been a significant change in the media system due to the emergence and development of the Internet media, which not only took its place in it, but also determined the leading trends in its functioning. It is also important to study
\end{abstract}

the influence of special features of network journalism on the media system in terms of their historical development and the mutual influence of Internet journalism and the technologies of the global network. The increasingly active use of multimedia technologies in the media and the very transformation of the multimedia character continue to change the format of journalistic activity. It is relevant to consider the influence of multimedia on the nature of structural and content changes that determine the forms of information delivery in regional media. The experience of the Internet media of the Republic of Tatarstan is generalized, which have broad opportunities to influence public opinion.

1 Kazan Federal University, Kremliovskaya Russian Federation. E-mail: nagovitsinatatyana@mail.ru.

${ }^{2}$ Kazan Federal University, Kremliovskaya Russian Federation. E-mail: gazizovda@yandex.ru. 
Keywords: Internet media, multimedia, convergence, target audience, information product, potential readers, hyperlinks.

\section{INTRODUCTION}

In connection with the emergence and active development of Internet media, they are gaining more and more new properties. One of the forms of giving news and analytical material, attracting the attention of the audience is multimedia. E.L. Vartanova argues that multimedia is the most important feature acquired by the media as a result of the convergence of text, sound and image transmitted simultaneously in an interactive mode over a coaxial or fiber-optic cable, via radio links, satellite systems, or a combination of these technologies $[1, \mathrm{p}$. 235].

Internet media, which appeared in the traditional media, are not only a part of them, but also in recent years have become dominant. The prerequisites for the emergence of multimedia were the rapid development of technologies, through which the Internet made possible the convergence of text, sound and images, which are transmitted simultaneously in an interactive mode. The new information and communication environment requires the media, first of all, to take into account the requirements of the modern media market. Today, the multimedia factor plays a special role in the diverse manifestations of content forms.

I. Kiriya believes that the multimedia language is interactive, because it allows you to obtain information using various options and various semantic schemes, and using the data by nature itself to the person of the opportunity [2, p. 20].

Today, multimedia has become one of the most successful concepts for the development of the media industry and the relationship between the media and the audience. Experts define it as "the integration of two or more communication tools and channels with a computer." [3, p. 2]. Now the word "multimedia" is understood as the transmission of information simultaneously by several communication channels: audio, video, and virtual communications. Therefore, multimedia can easly be presented as a single information system, which is based on any types of media whose 
information products partially "merge" with each other.

\section{METHODS}

The multimedia nature of the text assumes active use of non-verbal information. Compared with the press, the authors of the Internet texts do not attach importance to font-based variation, much less to the punctuation system. All this is replaced, but not compensated for in more straightforward ways to bring the content to the audience.

Elements of multimedia on the pages of the electronic newspaper "BUSINESS Online" (Republic of Tatarstan) can be seen in almost all relevant materials. So, in the material "Poll with" predilection": how Nyusha chose volunteers" is given a video about how the singer Nyusha enters the role of the "mundial" ambassador. In Kazan, she is engaged in the selection of volunteers for the Confederations Cup, and at the same time discussing the exploits of "Barcelona". Although she admitted that she "is not that close to football" [3].

To date, almost all media in the Republic of Tatarstan have Internet versions. This makes it possible for readers, listeners and viewers to get acquainted with the news and analysis of the region and the country at any time convenient for them.

The use of multimedia properties in the Internet media also causes the development of such a phenomenon in the media as convergence.

Convergence refers to "the process of integration, convergence of various technologies, their integration into a single technological platform. The process of convergence is a common feature of the modern information society, within which there is an increase in the interdependence of various elements of the system as a whole. Convergence is understood as the combination of different formats (newspaper on the Internet), and the economic union of previously isolated sectors (telephony, radio and cable television) "[4, p. 206]. Today, multimedia has become one of the most successful concepts for the development of the media industry and relationship between the media and the audience. Specialists define it as "the integration of two or more communication facilities and channels with a computer" [5, p. 2].

The ability to place video and audio information on the pages of the 
Internet media contributes to the fact that these publications can combine different functions, and not just work with text. Shooting photos and video reports has become a routine thing for a modern journalist. News portals "E-Kazan" and "ProKazan.ru" combine the functions of the newspaper, television and radio. This makes it possible to talk about convergent editions on the territory of the Republic of Tatarstan.

\section{RESULTS}

If we talk about the degree of study of the problem, today, with confidence, we can say that in the foreign and domestic literature, the media's media divergence and multimedia have been studied quite widely. Foreign media researchers S. Kuin [6], D. Fisher [7], A. Grpant, J. Wilkinson [8] in their writings give a detailed description of the process of convergence. M.Lyuki [9] and M.Brigts consider questions of convergence in practical terms [10].

Domestic scientists are also engaged in Vartanova. "What is the convergence of the media doing?" [11]. It examines various aspects of the convergence.

\section{DISCUSSION}

Considering convergence as a process of integration and convergence of various technologies, it is possible to distinguish three of its specific features: 1) Convergence leads to the merging of different media. 2) Requirements for the journalist change. Today he must have multimedia skills. 3) The convergence of the media gives rise to new integrated genres-the infotainment and edutainment. Journalists theorists believe that an important consequence of the convergence process was the change in the information product itself. Text, graphic, sound and video illustrations are integrated into a single information product, creating a new information environment, which is called "multimedia". Multimedia character of the text, as already mentioned above, involves the active use of non-verbal information means, which undoubtedly helps to reveal their potential. Hyperlinks also increase the amount of information offered and are now widely used in the Internet media. Considering hypertext links from the point of view of webdesign solutions, according to GA Makhini, two main approaches can be 
distinguished: the links are placed in the "body" of the text (they are usually distinguished by graphic elements-for example, another color) or they are carried out in the lateral menu, located outside, usually on the side of the main material. By the way hypertext links are used, one can compose an idea of what tasks the authors of the site place, organizing information flows. Hyperlinks can be contextual and thematic in nature [12. p. 97]. Issues of multimedia and convergence, as factors in the development of Internet media, certainly require attention, both theorists and practitioners of journalism. It seems that this topic will interest teachers and students-journalists and will continue.

\section{SUMMARY}

Thus, we came to the conclusion that in the Republic of Tatarstan, as well as in the whole of Russia, a considerable amount of experience of modern Internet media has been accumulated. Modern media companies expand their range of information and entertainment products and at the same time use "new" forms of media content: online newspaper, radio on the Internet, web television.
Today, convergence can be understood as the transmission of a single content by different means (using text, sound or video) and through various communication channels (press, television, radio, the Internet).

Multimedia is one of the main factors of the development and functioning of the networked media of the Republic of Tatarstan. It was formed in conditions of elaboration of competitive strategies and is characterized by a variety of tools, differentiation of its use depending on the specifics of the material, creative character.

The influence of multimedia on the genre and linguistic nature of materials is expressed, on the one hand, in the enhancement of the features inherent in the language of the Internetmedia in general, on the other hand, in a certain opposition to the trend of simplification.

\section{CONCLUSION}

Such elements of multimedia as photos and video materials, on virtual pages "Business Online", "Inde", "Kazan. 24 "appear in almost all the headings. Video, as a multimedia function, gives 


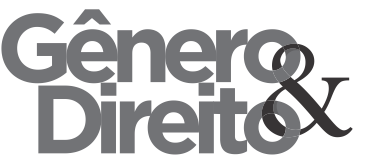

Periódico do Núcleo de Estudos e Pesquisas sobre Gênero e Direito

Centro de Ciências Jurídicas - Universidade Federal da Paraíba

V. 8 - No 05 - Ano 2019

ISSN | 2179-7137 | http://periodicos.ufpb.br/ojs2/index.php/ged/index the reader the opportunity to penetrate deep into the problem. The materials in this publication are distinguished by a large volume and depth of supply. In the context of addressing the multimedia problem of the Internet media of the Republic of Tatarstan, it is also worth highlighting the portal "Inkazan.ru", in which the media supplement is based on photo reports.

We believe that the role of the multimedia factor in the development of the Internet media requires further study. Considering it as one of the properties of networked mass media will make it possible to say that for today the prospect of the development of Russian federal and regional Internet media is precisely the wide application of new approaches to multimedia.

\section{CONFLICT OF INTEREST}

The authors confirm that the presented data do not contain a conflict of interest.

\section{Acknowledgments}

The work is carried out according to the Russian Government's Program of Competitive Growth of Kazan Federal University.

\section{REFERENCES}

Vartanova E.L. Media economics of foreign countries. - Moscow: Aspect Press, 2003.

Kiriya I. What is multimedia? / I. Kiriya // Journalism and convergence: why and how traditional media are transformed into multimedia. - Moscow: Higher School of Journalism, 2010.

«BUSINESS Online» from 9.03.2017: https://www.business-

gazeta.ru/video/339374?utm_campaign $=$ main-page $\&$ utm_source $=$ video

Lukanina MV Text of the media and convergence / MVLukanina. - Political Linguistics: Ekaterinburg, 2006.

Perspectives on Multimedia: Communication, Media and Information Technology by Robert Burnett (Editor), Anna Brunstorm (Editor), Enders G. Nilsson (Editor). - Wiley, England, 2004. P.2

Quinn S. Convergent Journalism: The Fundamentals of Multimedia Reporting. New York: PeterLang, 2005, 256 p. 
Fisher D., Grant A., Wilkinson J.

Principles of Convergent Journalism,

Oxford: Oxford University Press, 2008, $240 \mathrm{p}$

Grant, A., Wilkinson, J. Understanding

Media Convergence, New York, NY:

Oxford University Press, 2008, 320 p.

Luckie M. S. The Digital Journalist's

Handbook. Lexington, KY:

CreateSpace, 2010, 256 p.

Briggs M. Journalism Next: A Practical Guide to Digital Reporting and Publishing. Washington, DC: CQ Pres, 2009, 251r.

Vartanovy E.L. What is the convergence of the media doing? // Information society. - 1999. -Vyp. 5.-C.11 -14.

Makhinin G.A. Multimedia as a property of the development of networked media at the present stage (on the materials of Tatarstan's networked media). Dis. Candidate of Philology, Kazan, 2013 